\title{
PEMIKIRAN SUFISTIK MUHAMMAD SHALIH AL-SAMARANI
}

\author{
M. In'amuzzahidin \\ UIN Syarif Hidayatullah Jakarta \\ e-mail: inamuzzahidin@yahoo.com
}

\begin{abstract}
The ideas of sufism of Muhammad Shalih al-Samarani in Matn al-Hikam and Majmü'at al-Sharīah al-Käfiyah li 1-Awām is still rarely studied by researcher. The sufism of Muhammad Shalih al-Samarani emphasizes on implementing islamic doctrine with sincerity and submition to God. Muhammad Shalih bases his sufism on practical (sunniamali) sufism. He reject philosophical (falsafi) sufism, embraced by especially lay people.

$* * *$

Ide tentang sufismeMuhammad Shalih al-Samarani dalam Matn al-Hikam dan Majmü'at al-Sharīah al-Kāfiyah li l-'Awām masih jarang dikaji. Sufisme Muhammad Shalih alSamarani menekankan implementasi doktrin Islam dengan ketundukan kepada Tuhan. Muhammad Shalih mendasarkan sufismenya pada sufisme praktis (sunni-amali). Dia menolak sifisme filosofis (falsafi), yang khususnya dianut oleh masyarakat awam.
\end{abstract}

Keywords: $\quad$ faḍl, irādah, tadbīr, ikhlas, zuhud, waḥdatal-wujūd, khushu' 


\section{A. Pendahuluan}

Martin Van Bruinessen menginformasikan bahwa sebelum abad ke-17, sudah ada penulisan kitab-kitab keagamaan yang menggunakan bahasa Jawa. Hal ini dibuktikan, sekitar tahun 1600 terdapat beberapa manuskrip lama dari Jawa yang dibawa ke Eropa oleh para pelaut, yang sebagian besar berisi ajaran tentang: tauhid, tasawuf dan akhlak. ${ }^{1}$ Kitab-kitab yang berbahasa Jawa itu ada yang berasal dari hasil terjemahan dari kitab berbahasa Arab, seperti al-Taqrīb fi 'l-Fiqh dan kitab Tuhfah, dan ada yang bukan terjemahan. Terjemahan kitab Tuhfah sendiri tidak hanya ditulis dengan huruf Arab, tetapi ada yang ditulis dengan menggunakan huruf Jawa (hanacaraka), yang diterbitkan oleh S. Keyzer tahun $1853{ }^{2}$

Di antara ulama Indonesia yang melahirkan karya tulis besar yang menggunakan bahasa Jawa adalah Haji Ahmad Rifa'i Kalisalak (1786-1875). Dan satu-satunya penulis kitab-kitab agama yang menggunakan bahasa Jawa yang cukup produktif yang hidup pada abad ke-19 M. hingga awal abad ke-20 M. adalah Kiai Haji Muhammad Shalih ibn 'Umar al-Samarani (1820-1903). ${ }^{3}$

Kiai Semarang Jawa Tengah yang lebih dikenal dengan sebutan Kiai Saleh Darat ini, bernama Muhammad Shalih. Anak dari Kiai 'Umar ini, lahir di Kedung Cumpleng, Kecamatan Mayong Kabupaten Jepara Jawa Tengah, kirakira tahun 1820. Namun tentang kapan tanggal lahirnya secara pasti, belum diketahui. ${ }^{4}$ Beliau wafat di Semarang pada hari Jum'at Legi, tanggal 28 Ramadhan 1312 H, dan bertepatan dengan tanggal 18 Desember 1903, dalam usia sekitar 83 tahun. ${ }^{5}$

Kiai Saleh Darat setidaknya memiliki 14 karya, yang menerangkan berbagai macam kajian keislaman. Seperti tentang fiqh, tauhid, tasawuf, ulumul

1 Martin van Bruinessen, Kitab Kuning, Pesantren dan Tarekat: Tradisi-tradisi Islam di Indonesia, (Bandung: Mizan, 1415/1995), h. 113.

2 Bruinessen, ibid., h. 114; Lihat juga Muslich Shabir, "Studi Kitab Munjiyat: Menyingkap Konsep Kiai Saleh Darat Semarang tentang Perbuatan yang Membinasakan dan yang Menyelamatkan Manusia," dalam Jurnal Walisongo, Puslit IAIN Walisongo, 2007, Vol. XV, No. 1 Mei 2007, h. 85.

3 Muslich Shabir, "Studi Kitab Munjiyat...," h. 85; Ghazali Munir, Shalat Jum'at Bergantian, Implementasi Konsep Iman dan Amal Muhammad Salih Ibn Umar al-Samarani dalam Masyarakat Modern, (Semarang: Syiar Media Publishing, 2008), h. 47-48.

4 Abdullah Salim, Majmū'at al-Syarīah al-Kāfiyah li 'l-'Awām Karya Syaikh Muhammad Sālih Ibn Umar al-Samārānī, Seri Disertasi, (Jakarta: IAIN Syarif Hidayatullah, 1994), h. 20.

${ }^{5}$ Abdullah Salim, Majmü'at, h. 37. 
qur'an, tafsir qur'an, manasik haji dan umrah, kitab Barzanji, dan tentang isra' mi'raj Nabi. ${ }^{6}$

Di bidang tasawuf, Muhammad Shalih al-Samarani menulis beberapa kitab tersendiri, antara lain Hażihi Kitāb Munjiyyāt "metik saking kitab" Ihyyā' 'Ulūm al-Dīn al-Ghazālī, Minhāj al-Atqiyā' fi Sharh Ma'rifat al-Ażkiyā' ilā Ṭarīq alAwliyā', dan Hażā al-Kitāb Matn al-Hikam. Selain itu, Muhammad Shalih juga menulis Hażā Kitāb Majmü'at al-Sharī'ah al-Käfiyah li 'l-'Awām, yang memuat tentang kajian fiqh orang awam, disamping juga memuat ajaran tasawuf.

Penelitian yang akan penulis lakukan adalah meneliti pemikiran-pemikiran tasawuf Muhammad Shalih yang terdapat dalam kitab Matn al-Hikam dan kitab Majmū'at al-Sharī'ah al-Kāfiyah li 'l-'Awām.

Kitab Matn al-Hikam merupakan kitab tasawuf terjemahan dan ringkasan dari kitab al-Hikam karya Syaikh Ahmad ibn 'Atha'illah al-Sakandari (W. 709 H/1309 M) dengan menggunakan bahasa Jawa. Kitab ini diterjemahkan pada tahun $1289 \mathrm{H} / 1872 \mathrm{M}$ untuk kepentingan masyarakat Islam awam yang tidak menguasai bahasa Arab. ${ }^{7}$

Sedang kitab Majmü'at al-Sharīah al-Käfiyah li 'l-'Awām, sebagaimana dijelaskan Martin Van Bruinessen, merupakan satu-satunya karya penting berbahasa Jawa dengan huruf Arab (Arab pegon) tentang fiqh, yang ditulis oleh Muhammad Shalih Darat dari Semarang, ${ }^{8}$ selain memuat juga ajaranajaran teologi dan tasawuf atau akhlaq.

Penelitian ini menjadi penting, mengingat kedua kitab tersebut di atas, sampai saat ini masih dipergunakan sebagai literatur utama dalam majlis pengajian, seperti pengajian yang ada di Bareng Kudus atau daerah Losari Brebes, ${ }^{9}$ dan daerah lain bagi mereka yang tidak menguasai bahasa Arab. Artinya, ketika ada kesalahan dalam memahami kedua kitab tersebut di bidang tasawuf, misalnya, maka akan berdampak pula pada kesalahan keyakinan dan perilaku keagamaan mereka.

\footnotetext{
${ }^{6}$ Ghazali Munir, Tuhan, Manusia, dan Alam, dalam Pemikiran Kalam Muhammad Salih alSamarani, (Semarang: Rasail, 2008), h. 59-74.

${ }^{7}$ Ghazali Munir, Shalat Jum'at Bergantian, h. 51; Ghazali Munir, Tuhan, Manusia, dan Alam, h. 65; Muhammad Shalih al-Samarani, Hażā al-Kitāb Matn al-Hikam li Sayyidī al-Syaikh Ahmad ibn 'Athā'illāh al-Sakandarī, (Semarang: Thoha Putra, t.th.).

8 Martin Van Bruinessen, "Kitab Fiqih di Pesantren Indonesia dan Malaysia," Pesantren, Vol. VI, No. 1, 1989, h. 49.

${ }_{9}^{9}$ Lebih lanjut lihat Ghazali Munir, Tuhan, Manusia, dan Alam, h. 73.
} 
Selain itu, penelitian tentang pemikiran tasawuf Muhammad Shalih alSamarani, khususnya yang ada dalam kitab Matn al-Hikam dan kitab Majmū'at al-Sharī'ah al-Käfiyah li 'l-'Awām, baik yang berbentuk dalam disertasi maupun yang lain, nampaknya belum ada pada penelitian-penelitian sebelumnya. Penelitian terdahulu tentang pemikiran Muhammad Shalih alSamarani memang sudah pernah ada, antara lain: Abdullah Salim (1994) dengan judul penelitian (disertasi), Majmū'at al-Sharī'ah al-Käfiyah li 'l-'Awām karya Shaikh Muḥammad Șālih Ibn 'Umar al-Samārānī. H.M. Muchoyyar HS (2000) dengan judul penelitian (disertasi), K.H. Muhammad Salih al-Samarani, Studi Tafsir Faid al-Rahman fi Tarjamah Tafsir Kalam Malik al-Dayyan. ${ }^{10}$ Ghazali Munir (2008) dengan judul penelitian (disertasi) yang telah dipublikasikan, Tuhan, Manusia dan Alam, dalam Pemikiran Kalam Muhammad Salih al-Samarani. Kemudian Ghazali Munir (2008) juga telah meneliti pemikiran Muhammad Shalih tentang diperbolehkannya shalat jum'at bergantian dalam penelitiannya yang berjudul Shalat Jum'at Bergantian, Implementasi Konsep Iman dan Amal Muhammad Salih Ibn Umar al-Samarani dalam Masyarakat Modern. Penelitian ini juga telah dipublikasikan. Muslich Shabir (2007) dengan judul penelitian, Studi Kitab Munjiyat: Menyingkap Konsep Kiai Saleh Darat tentang Perbuatan yang Membinasakan dan yang Menyelamatkan Manusia, memfokuskan pada karya Muhammad Shalih alSamarani yang berjudul Kitab al-Munjiyat, dan menerangkan pemikirannya tentang perbuatan yang membinasakan dan yang menyelamatkan manusia. ${ }^{11}$ Sehingga kajian tentang tasawuf Kiai Saleh Darat, khususnya yang tertuang dalam kitab Matn al-Hikam dan Kitāb Majmū'at al-Sharīah al-Kāfiyah li 'l'Awām, belum nampak dalam penelitian di atas.

Tidak hanya itu, dalam kajian tasawuf ke-Indonesiaan, kajian tasawuf Muhammad Shalih al-Samarani juga kurang mendapat perhatian dari para peneliti. Hamka (1952) misalnya, saat menjelaskan perkembangan tasawuf di Indonesia dan memperkenalkan ahli-ahli tasawuf Indonesia, hanya menyebut nama Hamzah al-Fanshuri, Abdurrauf Singkel, Nuruddin al-Raniri. ${ }^{12}$ Nama Muhammad Shalih al-Samarani tidak muncul dalam tulisan itu.

10 H.M. Muchoyyar HS, "K.H. Muhammad Salih as-Samarani, Studi Tafsir Faid ar-Rahman fi Tarjamah Tafsir Kalam Malik ad-Dayyan," Disertasi, (Yogyakarta: Pascasarjana IAIN Sunan Kalijaga, 2000).

${ }^{11}$ Muslich Shabir, Studi Kitab Munjizat.

12 Hamka, Tasauf Perkembangan dan Pemurniannya, (Jakarta: Pustaka Panjimas, 1993), h. 213. 
Azyumardi Azra saat menjelaskan jaringan ulama Timur Tengah dan kepulauan Nusantara juga tidak memasukkan Muhammad Shalih al-Samarani dan pemikiran tasawufnya dalam penelitiannya. ${ }^{13}$ Namun, ini dapat dipahami, karena penelitiannya hanya membatasi tokoh-tokoh pada abad XVII dan XVIII. Sedang Muhammad Shalih al-Samarani termasuk tokoh abad XIX.

A. Rivay Siregar ketika menjelaskan tasawuf di Indonesia hanya menjelaskan peran Walisongo, kelompok-kelompok yang mengikuti ajaran tasawuf al-Ghazali, serta tarekat berkembang yang ada. ${ }^{14}$ Nama Muhammad Shalih alSamarani dan pemikiran tasawufnya tidak muncul dalam tulisannya.

Rosihon Anwar dan Mukhtar Solihin saat menjelaskan tasawuf di Indonesia, hanya menyebutkan 4 tokoh, yaitu Hamzah al-Fansuri, Nuruddin alRaniri, Syeikh Abdur Ra'uf al-Sinkili dan Syeikh Yusuf al-Makasari, tanpa menyebut dan menjelaskan Muhammad Shalih al-Samarani dan pemikiran tasawufnya. ${ }^{15}$

Demikian halnya dengan Sri Mulyati (2006) aat menjelaskan tasawuf Nusantara abad XVI hingga abad XIX dan XXI M, juga tidak menyebut dan menjelaskan pemikiran tasawuf Muhammad Shalih al-Samarani. Dan ketika menjelaskan tokoh tasawuf dari Jawa Tengah, Mulyati hanya menyebutkan satu tokoh, yakni Syeikh Muslih ibn 'Abdurrahman dari Mranggen, Demak, Jawa Tengah, ${ }^{16}$ pendiri Ponpes Futuhiyyah Mranggen Demak, tempat pendidikan penulis dulu.

Mengingat masih langkanya pembahasan tentang pemikiran tasawuf Muhammad Shalih al-Samarani, khususnya yang fokus pada kitab Matn alHikam dan Kitāb Majmū'at al-Sharī'ah al-Käfiyah li 'l-'Awām, maka tidak berlebihan, jika penulis ingin menelitinya lebih lanjut.

${ }^{13}$ Azyumardi Azra, Jaringan Ulama Timur Tengah dan Kepulauan Nusantara Abad XVII dan XVII, (Bandung: Mizan, 1999).

${ }^{14}$ A. Rivay Siregar, Tasawuf Dari Sufisme Klasik ke Neo Sufisme, edisi revisi, (Jakarta: Raja Grafindo Persada, 2002).

${ }^{15}$ Rosihon Anwar dan Mukhtar Solihin, Ilmu Tasawuf, (Bandung: Pustaka Setia, 2006), h. 8.

16 Sri Mulyati, Tasawuf Nusantara, Rangkaian Mutiara Sufi Terkemuka, (Jakarta: Kencana Prenada Media Group, 2006), h. viii. 


\section{B. Pandangan Muhammad Shalih al-Samarani tentang Tasawuf dalam kitab Matn al-Hikam}

\section{Gambaran Umum Kitab Matn al-Hikam}

Nama lengkap kitab Matn al-Hikam ini adalah Hadhā al-Kitāb Matn alHikam li Sayyidī al-Shaikh Ahmad ibn 'Ațāillāh al-Sakandarī, Tarjamah bi Lisān al-Jāwī al-Mrīkī. Dalam cover kitab ini, tertulis nama penerjemahnya, yaitu: al'Alim al-'Alamah al-Fadlil al-Syaikh al-Wara' al-Kamil Muhammad Shalih ibn 'Umar al-Samarani.

Adapun kitab yang penulis pegang dan penulis jadikan bahan penelitian adalah kitab yang diterbitkan oleh Thoha Putra Semarang, yang telah mendapat persetujuan dari ahli waris penerjemah. Jumlah halamannya ada 152. Tanpa ada tahun penerbitannya. Dan sebelum diterbitkan Toha Putra, kitab terjamahan ini telah ditashhih oleh pemilik Maktabah al-Munir Semarang.

Kitab ini merupakan terjamahan dan ulasan ringkas yang diambilkan dari kitab Matn al-Hikam karya Ibn 'Atha'illah al-Sakandari, dengan menggunakan tulisan Arab pegon dan berbahasa jawa. Kitab ini diterjemahkan pada tahun 1289 H/1872 M untuk kepentingan masyarakat Islam awam yang kurang atau tidak bisa berbahasa Arab, agar mudah dipahami. ${ }^{17}$

Adapun kitab terjamahan Matn al-Hikam Kiai Saleh Darat ini, tidak membahas seluruh bait Hikam yang berjumlah 264.18 Dalam kitab ini, Kiai Saleh hanya mengulas 134 bait saja, dengan memilih pembahasanpembahasan tertentu.

Ketika membaca kitab terjamah Matn al-Hikam Kiai Saleh, penulis menemukan sedikit kesulitan untuk memahami secara langsung apa yang dikehendaki oleh Kiai Saleh. Karena, penulisan kitab tersebut tidak dilengkapi dengan tanda baca yang lengkap, seperti titik atau koma. Sehingga, kehatihatian dan ketelitian saat membaca teks sangat diperlukan dalam membaca kitab tersebut, agar maksud dan tujuan penulisnya dapat dipahami dengan baik.

17 Muhammad Shalih, Matn al-Hikam, h. 2.

18 Berkaitan dengan jumlah keseluruhan aforisme yang ada dalam al-Hikam, para ulama' berbeda pendapat. Ada yang menghitung berjumlah 264, ada juga yang mengkelompokkan menjadi 262 aforisme (dalam 25 bab), 4 risalah dan 34 munajat. Victor Danner, Ibn 'Athä'illāh's Sufi Aphorisms (Kitāb al-Hikam), Leiden: E.J. Brill, 1984, h. 20-21. 


\section{Setting Penulisan Kitab Matn al-Hikam}

Melihat dari karya-karya Kiai Saleh Darat yang ada, semuanya menggunakan bahasa Jawa, dengan huruf Arab pegon. Ini menunjukkan bahwa maksud penulisan karya-karya beliau memang disengaja ditujukan bagi orang Jawa. Beliau bermaksud, bagaimana ajaran-ajaran Islam yang terdapat dari berbagai lireratur Arab, dapat dikonsumsi dan dipahami oleh orang Islam pada umumnya dan orang Jawa pada khususnya, yang kurang — bahkan tidak sama sekali—menguasai bahasa Arab.

Tidak terkecuali dengan kitab terjamahan Matn al-Hikam ini, karya Ibn 'Atha'illah al-Sakandari. Kitab ini memang sengaja ditulis dengan menggunakan bahasa Jawa, agar mudah dipahami oleh mereka yang kurang menguasai kitab aslinya yang menggunakan bahasa Arab. Selain itu, kitab terjamahan ini tidak ditulis secara keseluruhan. Kiai Saleh dalam muqaddimahnya menjelaskan, kitab terjamahnya ditulis secara ringkas, seperlunya saja, dengan menggunakan bahasa Jawa, agar mudah dipahami oleh orang awam. ${ }^{19}$

Selain itu, penerjemahan kitab Matn al-Hikam yang dilakukan oleh Kiai Saleh adalah untuk memenuhi tuntutan dan kebutuhan masyarakat Muslim ketika itu pada khususnya, yang ingin menekuni dunia tasawuf, khususnya yang bersumber dari kitabnya Ibn 'Atha Allah al-Sakandari. Karena, sebagaimana dikatakan oleh Martin van Bruinessen (1995), popularitas kitab alHikām menempati urutan kedua setelah kitab Ihyō' 'Ulūm al-Dīn, karya alGhazali. Keduanya dijadikan sebagai kitab rujukan tasawuf dan diajarkan di pesantren-pesantren tradisional di Indonesia. ${ }^{20}$

\section{Ajaran Tasawuf dalam Kitab Matn al-Hikam}

Ajaran-ajaran tasawuf yang terdapat dalam kitab Matn al-Hikam antara lain:

\section{a. Pentingnya Bersandar kepada Allah}

Kiai Saleh Darat (w. 1312 H/1903 M) menjelaskan, bahwa amal seseorang hendaknya jangan dijadikan sebagai sandaran untuk berharap

${ }^{19}$ Muhammad Shalih, Matn al-Hikam, h. 2.

${ }^{20}$ Martin Van Bruinessen, Kitab Kuning, h. 163. 
mendapatkan surga atau selamat dari siksa api neraka. Karena ternyata, banyak orang-orang terdahulu yang beribadah, tapi mereka juga tidak luput dari siksa Allah. Oleh karenanya, kata Kiai Saleh, seseorang hendaknya hanya bersandar dan berpegang teguh serta bergantung kepada Allah, bukan kepada selain-Nya, termasuk dengan persoalan rezeki.21

Ibadah seseorang tidak dapat menjamin masuk surga, dan kemaksiatan juga tidak menyebabkan orang masuk neraka. Iman dan kufur, masuk surga atau neraka adalah karena anugerah ( $f a d ̣)$ Allah dan keadilan Allah semata. Taat dan maksiat hanyalah alamat bagi orang yang akan masuk surga atau neraka. ${ }^{22}$

Kenikmatan yang diperoleh seseorang hanyalah karena anugerah atau fạ̣l, bukan karena amal seseorang. Karenanya, seseorang tidak patut meminta pahala atas amalnya. Sebab, hakikatnya orang tidak memiliki amal, tetapi Allahlah yang memberikan amal. Oleh karena itu seseorang hendaknya bersyukur atau berterima kasih kepada Tuhan atas pemberian-Nya itu. ${ }^{23}$

\section{b. Eksistensi Manusia}

Berkaitan eksistensi manusia di hadapan Allah SWT., Muhammad Shalih menyatakan bahwa Allah menciptakan manusia bukanlah karena kehendak dan rekayasa manusia sendiri, melainkan karena kehendak Allah semata. ${ }^{24}$

Allah menciptakan rasa kasih sayang kepada kedua orang tuanya, sehingga mereka dapat mengasuhnya dengan penuh kasih dan sayang sampai dewasa. Tuhan juga memberikan kecerdasan atau akal, iman dan ilmu yang semuanya itu merupakan kehendak atau irādah Tuhan semata, bukanlah hasil kehendak dan rekayasa manusia. ${ }^{25}$

Karena manusia adalah milik Allah, maka Allah lah yang akan mencukupi segala kebutuhannya. Oleh karena itu, hendaknya manusia yakin terhadap kekuasaan Allah, bahwa Allah telah mentaqdirkan dan mengira-ngira

${ }^{21}$ Muhammad Shalih, Matn al-Hikam, h. 2-4.

${ }^{2}$ Ibid., h. 5-6.

${ }^{23}$ Ibid.,, h. 4-5, lihat juga Ghazali Munir, ShalatJum'at Bergantian, h. 51.

${ }^{24}$ Muhammad Shalih, Matn al-Hikam, h. 9-10.

25 Ibid., h. 8-10; Ghazali Munir, Shalat Jum'at Bergantian, h. 52. 
kebutuhan semua makhluknya yang ada di atas bumi ini, termasuk manusia. ${ }^{26}$

Demikian halnya dalam persoalan rezeki. Semua kebutuhan rezeki manusia, baik orang iman/taat atau orang kafir, sudah ditanggung oleh Allah. Hanya masalah ibadah lah yang dituntut dari seorang hamba untuk diperhatikan dan dikerjakan dengan sungguh-sungguh, bukan memilihkan Allah untuk dirinya sendiri. ${ }^{27}$

Dalam pandangan Kiai Saleh, setidaknya ada 10 sebab, mengapa manusia harus pasrah kepada Allah dan mengistirahatkan dirinya dari hal-hal yang belum terjadi dengan nafsu, syahwat, dan ikhtiar: (1) Manusia harus paham, bahwa Allah telah merencanakan segala sesuatunya sebelum manusia terwujud; (2) Ketika manusia mengatur dirinya, maka hal itu menunjukkan kebodohannya tentang kebaikan Allah yang selalu diberikan kepada semua makhluk-Nya. Dengan memasrahkan segala urusan kepada Allah, maka Allahlah yang akan mencukupi kebutuhannya;28 (3) Taqdir (ketetapan) Allah tidak akan berlaku pada tadbïr (pengaturan manusia). Banyak kejadiankejadian yang dialami manusia di luar rencananya; (4) Allahlah Dzat yang memerintah seluruh kerajaan langit tujuh, tujuh bumi, 'arasy, dan kursi, dengan kekuasaan penuh. Manusia sangat kecil di hadapan Allah, yang sangat Kuasa atas segala sesuatu. Semua akan tunduk dan patuh terhadap perintah Allah, dan pasrah dengan pengaturan Allah; (5) Badan manusia adalah milik Allah semata. Buktinya, manusia tidak bisa membuat dan menjamin badannya sehat. Karena bukan milik manusia, maka manusia tidak berhak untuk mengatur, memerintahkan dan mengatur dirinya; ${ }^{29}$ (6) Manusia hidup di dunia bagaikan tamu yang hanya sekedar mampir bertamu di desanya Allah dan bertamu kepada Allah. Seorang tamu pasti akan dijamu dan dijamin oleh pemilik rumah. Sehingga yang bertamu tidak usah pusing berfikir tentang kecukupan hidupnya. Sebagaimana diketahui, kata Rasul, toleransi seseorang untuk bertamu dan mendapat fasilitas dari tuan rumah adalah 3 hari. Padahal 1 hari bagi Allah adalah sama dengan 1.000 tahun. Dan 1.000

${ }^{26}$ QS. al-'Ankabut [29]: 60; QS. Hud [11]: 6.

27 Muhammad Shalih, Matn al-Hikam, h. 17-18.

${ }^{28} \mathrm{Ibid}$., h. 12; QS. al-Thalaq [65]: 3 Artinya: "dan barang siapa yang bertawakkal kepada Allah niscaya Allah akan mencukupkan (keperluan)nya."

${ }^{29}$ Muhammad Shalih, Matn al-Hikam, h. 12-13. 
tahun $x 3=3.000$ tahun. Sedangkan umur manusia tidak ada 3.000 tahun. Sehingga manusia hendaknya tidak perlu terlalu mengatur atau menentukan dirinya; (7) Manusia hendaknya sadar bahwa Allah adalah Dzat yang Maha Hidup dan Maha berdiri dengan sendirinya, yang menguasai semua makhlukNya. Allah yang menanggung dunia dan akhirat serta isinya. Allah yang memberi pahala dan pembalasan. Karena itu, manusia hendaklah pasrah kepada-Nya; (8) Manusia hendaknya sibuk dengan beribadah kepada Allah hingga mati menjemputnya. Sebagaimana dikatakan oleh Allah, beribadahlah kamu kepada Tuhanmu hingga datang keyakinan kepadamu. Ketika manusia sibuk dengan urusan ibadah, maka ia tidak akan mengangan-angan untuk mengatur dirinya; ${ }^{30}$ (9) Manusia harus sadar, bahwa ia adalah seorang hamba Allah. Dan di antara hak seorang hamba adalah tidak boleh ikut campur urusan Allah, Sang Pencipta. Karena kewajiban manusia hanyalah menjalankan perintah-Nya, seperti menjalankan perintah shalat; (10) Suatu ketika manusia melihat dan menyangka terhadap sesuatu itu akan bermanfaat, tapi ternyata justru menimbulkan madlarat, atau sebaliknya. Maka hendaknya manusia tidak usah mengatur dirinya. Meninggalkan pilihan diri sendiri dan menerima pengaturan Allah adalah ibadah yang lebih utama. ${ }^{31}$

\section{c. Ikhlas dalam Beramal}

Setiap amal ibadah memiliki ruh. Dan ruh amal adalah ikhlas. Dalam beramal, seseorang harus melandasinya dengan keikhlasan. Tanpa ikhlas, maka amal itu tidak ada manfaatnya.

Ikhlas itu sendiri, sebagaimana dijelaskan Kiai Saleh, terbagi menjadi tiga. Pertama, ikhlasnya orang-orang yang beribadah. Artinya, amalnya ahli ibadah hendaknya selamat dari riyā' (pamer) khafi (samar) maupun jali (terang-terang), 'ujūb (heran dengan amalnya sendiri). Ia beramal hanya karena Allah, menginginkan pahala-Nya dan takut terhadap siksa-Nya. Dan pahala memperoleh surga dan selamat dari neraka adalah karena prestasi ibadah. Sebagaimana dalam ayat iyyāka na'budu. Kedua, ikhlasnya muhibbin (orang-orang yang cinta kepada Allah). Artinya seseorang beribadah karena mencintai Allah, beramal karena Allah dan mengagungkan-Nya, bukan untuk

\footnotetext{
30 Ibid., h. 14-15.

${ }^{31}$ Ibid., h. 15-17.
} 
memperoleh pahala atau agar selamat dari siksa-Nya. Hal ini sebagaimana dikatakan oleh Rabi'ah 'Adawiah. Ia mengatakan: "aku beribadah kepada-Mu, tidak karena takut terhadap neraka-Mu, atau ingin masuk surga-Mu. Tetapi aku menyembah-Mu, karena mengagungkan-Mu. Ketiga, ikhlasnya orang yang ma'rifah ('ārif). Artinya seseorang melihat adanya amal hanyalah semata-mata karena kehendak Allah (bi Allāh). Allahlah yang menggerakkan atau mendiamkan seseorang. ${ }^{32}$

\section{d. Doa}

Setiap doa yang dipanjatkan oleh seorang hamba kepada Allah, pasti akan diijabahi oleh Allah. Hanya saja, hanya doa yang dikehendaki dan dipilih oleh Allah saja yang dikabulkan. Dan tentang waktunya juga terserah Allah. Manusia tidak dapat menentukannya. Namun demikian, ketika doa itu belum terkabul, hendaknya seseorang tidak berputus asa untuk terus memohon dan berdoa kepada Allah.

Mengapa demikian. Karena kebanyakan manusia tidak mengetahui doa mana yang bermanfaat baginya atau tidak. Oleh karena itu, Allah hanya akan mengabulkan doa yang bermanfaat bagi yang bersangkutan. ${ }^{33}$

Oleh karena itu, ketika Allah belum atau tidak memberi apa yang kita minta, maka artinya Allah memberikan kasih sayang-Nya kepada kita. Karena hakikatnya Allah lebih sayang dan lebih kasih daripada seorang ibu kepada anaknya. Artinya Allah tidak memberi sama dengan memberi. Semua yang ada sesuai dengan ilmu dan hikmah-Nya, serta rencana-Nya yang penuh dengan kebaikan. ${ }^{34}$

\section{e. Zuhud}

Kiai Saleh Darat menjelaskan, amal yang keluar dari hati orang yang tidak suka dunia atau zuhud itu lebih agung meskipun sedikit secara lahiriah. Karena amal orang yang zuhud selamat dari riyā' atau pamrih karena manusia, selamat dari tujuan duniawi, dan selamat dari berpaling dari selain

\footnotetext{
${ }^{32}$ Ibid., h. 30-32, 58-60.

33 Ibid., h. 19.

34 Ibid., h. 24-25.
} 
Allah. Berbeda dengan amal yang keluar dari hati orang yang mencintai dunia. Amalnya menjadi sedikit, meskipun banyak secara lahiriah. Karena amal orang yang suka dunia, tidak selamat dari riyā' atau pamrih karena manusia, berorientasi duniawi, dan berpaling kepada selain Allah. ${ }^{35}$

\section{f. Syukur}

Kiai Saleh Darat menjelaskan, syukur terhadap nikmat-nikmat yang diberikan Allah akan menjadikan langgengnya nikmat itu sendiri. Sedang meninggalkan syukur berarti akan menghilangkan nikmat itu. Dan nikmat yang paling agung dan mulia adalah nikmat Islam dan iman. Adapun bentuk syukur ada tiga macam. Pertama, syukur dengan hati, yakni yakin bahwa nikmat yang ada adalah berasal dari Allah SWT., kedua syukur dengan lisan, yakni dengan cara mengucapkan syukur yang telah diterima. Ketiga, syukur dengan anggota badan, yakni dengan cara menjalankan segala bentuk ketaatan dengan anggota badan. Seperti lisan digunakan untuk membaca alQur'an, shalawat, dzikir, tasbih dan lain-lain. Mata untuk melihat keajaiban berbagai ciptaan Allah, dan untuk membaca al-Qur'an, bukan untuk melihat hal-hal yang diharamkan. Telinga digunakan untuk mendengarkan perintahperintah Allah dan kemudian menjalankannya. Kaki digunakan untuk ibadah berjalan seperti mencari ilmu, dan berjamaah di masjid. Tangan digunakan untuk mencari nafkah, bekerja yang halal. Dan ketika anggota tubuh itu digunakan untuk melakukan hal-hal yang diharamkan, berarti pelakunya telah mengkufuri nikmat. ${ }^{36}$

Dan ketika seseorang dapat menjalankan perintah-Nya dan menjauhi larangan-Nya, bersandar sepenuhnya kepada Allah, bukan bersandar dan berpegang pada ketaatannya, maka ia telah mendapatkan kesempurnaan nikmat secara lahir dan batin. ${ }^{37}$

Menurut Kiai Saleh Darat, ada dua nikmat yang pasti dirasakan oleh semua yang mawjūd, yaitu: nikmat ījād dan nikmat imdād. Nikmat ījād adalah mewujudkan sesuatu yang asalnya tidak ada ('adam) menjadi ada (mawjūd). Kemudian setelah ada, ia butuh pengekalan wujūd itu sendiri, dan butuh

35 Ibid., h. 62.

36 Ibid., h. 70-71.

37 Ibid., h. 74. 
nikmat imdād. Yaitu nikmat yang menghilangkan 'adam dan diganti dengan nikmat mawjūd yang langgeng. Sehingga, andaikata tidak ada nikmat $\bar{j} j a \bar{d}$, maka tidak akan ada sesuatu pun yang mawjūd. Dan andai tidak ada nikmat imdād, maka segala sesuatu yang mawjūd tidak akan sempurna dan langgeng. ${ }^{38}$ Dan di antara kesempurnaan nikmat itu adalah Allah memberikan rezeki sesuai dengan kebutuhan, dan mencegah perbuatan yang keji sebab melimpahnya rezeki. ${ }^{39}$

\section{g. Muhāsabah bi Nafsih}

Kiai Saleh Darat juga menjelaskan, mengetahui kejelekan diri sendiri itu lebih baik daripada bersungguh-sungguh ingin mengetahui hal-hal yang samar (gaib), atau pun mengetahui taqdir yang masih samar, yang merupakan bagian dari bentuk karāmah. Adapun sifat jelek itu antara lain seperti: 'ujūb, kagum terhadap prestasi ibadah diri sendiri; riyā', ingin dipuji manusia; takabbūr, merasa dirinya lebih unggul daripada yang lain, walaupun dengan anjing sekalipun; hasud, mengharap hilangnya kenikmatan orang lain; kufur nikmat; merasa susah saat mendapat cobaan dan mengadu kepada selain Allah; senang terhadap dunia; senang pujian dan sanjungan; takut dihina manusia; susah dalam urusan dunia; takut fakir; benci terhadap ketentuan Allah; senang keabadian di dunia untuk memperbanyak harta benda; berlaku kasar terhadap orang lain; senang bermusuhan dan banyak bicara; senang mengetahui kesalahan dan 'aib orang lain dan tidak senang mengetahui kekurangan diri sendiri; senang berkumpul dengan manusia dan sedih saat berpisah; sedikit malu dan sedikit belas kasihnya terhadap makhluk; tergesa-gesa saat melakukan amal kebaikan dan memperlambat saat akan berbuat kebaikan. ${ }^{40}$

\section{h. Mewaspadai Karāmah}

Kiai Saleh Darat menjelaskan, ketika seorang sālik bersunguh-sungguh dzikir dan amal shalih, kemudian ia merasakan hatinya terang dan terbuka

38 Ibid., h. 84.

39 Ibid., h. 137.

40 Ibid., h. 45-46.

Walisongo, Volume 20, Nomor 2, November 2012 
hatinya, serta melihat hal-hal yang samar, baik yang ada di langit maupun yang ada di bumi, dan ia merasa, bahwa ia telah sampai pada tujuan akhir perjalanan spiritualnya, maka suara hakikat dari Allah akan mengatakan, bahwa "apa yang kamu cari, ada di depanmu."41

Lebih lanjut Kiai Saleh Darat mengatakan, bahwa ketika seorang sālik atau murìd mengalami hal-hal yang luar biasa, seperti tunduknya semua makhluk padanya, keluasan rezeki, berjalan di atas air, memperbanyak sesuatu yang sedikit, membuat jarak yang jauh menjadi dekat saat bepergian, hendaknya jangan dihiraukan. Karena semua itu adalah ujian atau fitnah. Karenanya, seorang sālik hendaknya tidak berpaling kepada selain Allah, atau hanya sekedar disibukkan dengan urusan meminta rezeki kepada Allah. ${ }^{42}$

\section{i. 'Uzlah}

Kiai Saleh Darat (W. 1312 H/ 1903 M) menjelaskan, bahwa 'uzlah, menyendiri, menjauhi hiruk pikuk bercampur dengan manusia, sangat bermanfaat bagi kekejernihan hati seorang murīd. Karena bercampur baur dengan manusia, maka pikiran murīd akan sibuk mengangan-angan apa yang dilihat oleh matanya. Berbeda dengan menyendiri. Pikirannya hanya akan tertuju pada akhirat, yang menjadi sebab terangnya hati. 43

\section{Pandangan Muhammad Shalih al-Samarani tentang Tasawuf dalam Kitab Majmü'at al-Sharī'ah al-Kāfiyah li 'I-'Awām}

\section{Gambaran Umum Kitab Majmū'at}

Nama lengkap kitab Majmū'at adalah Hadzā Kitāb Majmū'at al-Sharī'ah al-Kāfiyah li 'l-'Awām Mutarajjimah bi Lughat al-Jāwiyyah al-Mrīkiyyah li 'lShaykh al-'Ālim al-'Allāmah Haji Muhammad Șālih Ibn 'Umar al-Samārānī. Adapaun makna bi Lughat al-Jāwiyyah al-Mrīkiyyah adalah menggunakan bahasa Jawa sini (mriki-Semarang). Kitab yang ada pada penulis, diterbitkan oleh Syaikh 'Abdullah ibn 'Afif, pemilik penerbit al-Maktabah al-Mishriyyah bi

41 Ibid., h. 38.

42 Ibid., h. 39.

43 Ibid., h. 33. 
Syirbun. Kitab tersebut telah diteliti ulang (di-tașhīh) oleh Haji Mahmud ibn Haji Kiai Muhammad Ra'is, tertanggal Shafar $1374 \mathrm{H}$.

Kitāb Majmū'at al-Sharī'ah al-Kāfiyah li 'l-'Awām itu sendiri ditulis oleh juru tulisnya yang bernama Jazuli, pada tanggal 8 Sya'ban sanah gusthi Hijrah. $^{44}$ Kata gusthi adalah kode angka Arab yang biasa dikenal dengan $a b a$ ja dun ha wa zun dan seterusnya. Huruf ghain adalah kode angka 1000. Huruf sin adalah kode angka 300, dan huruf ta' adalah kode angka 9. Maka makna sanah gusthi Hijrah artinya sama dengan $1000+300+9=$ th $1309 \mathrm{H}(1891$ M), kira-kira abad ke-19.45

Kitāb Majmū'at ini berisi 97 bagian, yang didominasi dengan ajaran fiqh. Maka sangat tepat, jika Martin Van Bruinessen mengatakan, ia merupakan satu-satunya karya terpenting berbahasa Jawa tentang fiqh, yang ditulis oleh Muhammad Saleh Darat Semarang. ${ }^{46}$ Pernyataan ini ada benarnya. Karena sebagian besar kitab tersebut adalah fiqh, walaupun di dalamnya terdapat persoalan-persoalan ushuluddin (teologi) dan akhlaq (tasawuf), disamping memasukkan unsur atau ajaran lokal Jawa, seperti acara sesajen atau sedekah bumi pada dayang/leluhur. ${ }^{47}$

Dalam proses penulisannya, terdapat banyak kekurangan tanda baca, seperti titik (tanda berakhirnya kalimah) atau salah penulisan, seperti kata fạ̣ilah tertulis faḍilat (dengan memakai ta' mabsūțah, seharusnya memakai ta' marbūțah); atau al-nikāh, tertulis a nikāh; khiṭah tertulis khuțbah. Bagi pembaca yang tidak tahu bahasa jawa atau makna gandul (istilah pesantren memberi makna kitab kuning-kitab salaf), akan mengalami kesulitan dalam memahami kalimah-kalimah yang ada dalam kitab tersebut. Selain itu, penulisan sub-sub bab kitab, seringkali hanya ditulis dengan fașlun atau bāb, tanpa menyebut pokok bahasan yang terdapat di dalamnya. Sehingga untuk mengetahui apa yang dimaksud sub bab tersebut, pembaca harus membaca dan memahami langsung bacaan yang terkandung di dalamnya.

\footnotetext{
${ }^{44}$ Haji Muhammad Shalih ibn 'Umar al-Samarani, Hadhā Kitāb Majmū'at al-Sharīah al-Kāfiyah li al-'Awām Mutarajjimah bi Lughat al-Jāwiyyah al-Mrīkiyyah, (Syirbun: al-Maktabah al-Mishriyyah, t.th.), h. 279.

45 Muhammad Shalih, Kitāb Majmū'at..., h. 7-8.

46 Martin Van Bruinessen, Pesantren, h. 49.

47 Muhammad Shalih, Kitāb Majmū'at..., h. 23-24.
} 
Adapun isi kitab majmü'at itu sendiri diambilkan dari beberapa kitab salaf yang ada, baik yang berkaitan dengan masalah fiqh, teologi atau tasawuf. Kitab-kitab itu antara lain: Ihyyā' 'Ulüm al-Dīn karya al-Ghazali dalam masalah nikah, asrār al-nikāh, asrār al-șalāh dan asrār al-ḥajj; kitab Sharḥ Minhāj (Fatḥ al-Wahhāb), Sharh al-Khațīb Sharbinī, dan al-Durar al-Bahiyyah, dalam masalah fiqh dan ushuluddin. ${ }^{48}$

\section{Setting Penulisan Kitab Majmū'at}

Kitab Majmū'at tidak jauh beda dengan terjamah kitab Hikam. Kiai Saleh Darat menulisnya menggunakan bahasa Jawa, dengan huruf Arab pegon. Tujuan penulisan tersebut juga terlihat dalam kitab Majmü'at, bagian penutup, yakni kata penutup pengarang dan mutarajjim al-Mutūn al-'Arabiyyah al-Jāwiyyah al-Mrikkiyyah, dengan ucapannya: "supoyo pahamo wong-wong amtsal ingsun awam kang ora ngerti basa Arab." (supaya paham orang-orang awam seperti saya yang tidak mengerti bahasa Arab). ${ }^{49}$

Di samping itu, karena pada saat penulisan kitab Majmūat ini berlangsung pada tahun 1309 H/1892 M. dan dicetak pada tahun 1899 M., maka bersamaan dengan itu pula, penjajahan Belanda masih terjadi di Indonesia. ${ }^{50}$ Sebagai seorang penulis yang paham situasi dan kondisi negaranya, Kiai Saleh, secara implisit, juga memasukkan pesan moral agar melawan penjajah dalam kitab Majmü'at-nya. Saat menerangkan orang murtad dalam perbuatan yang bisa membawa kekufuran, beliau mengharamkan umat Islam untuk menyerupai tingkah laku dan pakaian orang-orang kafir (non-Muslim), walaupun dalam hatinya tidak suka. Seperti memakai pakaian jas, topi, atau dasi. Dalam penjelasannya, beliau mengutip sebuah hadits Nabi yang berbunyi: "laysa minnā man tashabbaha bi ghayrinā- tidak termasuk umatku, orang yang menyerupai tingkah laku selainku." ${ }^{51}$

${ }^{48}$ Muhammad Shalih, Kitāb Majmū'at..., h. 278.

49 Ibid., h. 278.

${ }^{50}$ Abdullah Salim, Majmū'at, h. 8.

${ }^{51}$ Muhammad Shalih, Kitāb Majmū'at.., h. 24-25. 


\section{Ajaran Tasawuf dalam Kitab Majmü'at al-Sharīah al-Käfiyah li 1-'Awām}

\section{a. Larangan Belajar dan Menganut Paham Wahdat al-Wujūd}

Menurut Kiai Saleh, seseorang yang menyakini atau mengucapkan, bahwa sesungguhnya ruhnya adalah Allah, atau tidak ada Allah kecuali dirinya-sebagaimana ucapan Syaikh Siti Jenar-maka ia menjadi kafir. Beliau menolak keras belajar tasawuf falsafi bagi orang awam, sebagaimana menolak orang-orang yang punya pendirian dan sealiran dengan Siti Jenar seperti itu. ${ }^{52}$

Selain itu, Kiai Saleh juga mengharamkan orang awam untuk belajar waḥdat al-wujūd dan ilmu murtabah, seperti belajar kitab Tuhfat al-Mursalah atau al-insān al-kāmil. Karena, bagi orang awam, lanjut Kiai Semarang ini, perbuatan zina atau mencuri itu lebih baik daripada mengetahui dan belajar ilmu yang tidak benar penalarannya. Dan yang wajib bagi orang awam adalah, mengikuti perintah-perintah Allah SWT., dan menjauhi larangan-Nya. Ia tidak perlu mengikuti ilmunya para khawāṣ al-mu'mininn. ${ }^{53}$

\section{b. Syariat, Tarekat dan Hakikat}

Bagi Kiai Saleh, sharīat, țarīqat dan haqìqat, merupakan sesuatu yang harus ada dan dimiliki oleh setiap Muslim. Lebih lanjut, beliau memperumpamakan ketiganya begini. Ilmu sharîat itu bagaikan kapal yang dipergunakan untuk berlayar di lautan. Karenanya, masing-masing orang, harus memperbaiki dan merawat kapalnya beserta barang-barangnya, agar selamat dalam perjalanan. Ilmu țarīqat adalah bagaikan lautan itu sendiri, yang dilewati oleh kapal tadi. Oleh karena itu, untuk masuk ke țariqat, seseorang harus benar-benar membenahi terlebih dahulu sharīat-nya. Sedangkan ilmu haqiqat adalah bagaikan intan mutiara yang ada dalam lautan. Maka, bila seseorang ingin mendapatkannya, ia harus meninggalkan kapal dan barang bawaannya, lalu masuk ke laut dan menyengaja akan mengambil intan di dalamnya. Ilmu sharīat adalah perbuatan jasmani; ilmu țarīqat adalah per-

52 Ibid., h. 26.

53 Ibid., h. 27.

Walisongo, Volume 20, Nomor 2, November 2012 
jalanan spiritual hati yang batini sifatnya, sedang ilmu haqiqat adalah perjalanan rūḥ rabbānī (sirr). ${ }^{54}$

\section{c. Makna Khushu' dalam Shalat}

Pengertian khushu' banyak didefinisikan oleh banyak ulama'. Ada yang mengatakan, arti khushu' adalah mengikuti (perintah) Allah; atau hadirnya hati di hadapan Allah; atau adanya sifat takut selamanya yang ada dalam hati. 55

Perbuatan khushu' ini, sangat dibutuhkan dalam melaksanakan shalat, sebagaimana tercantum dalam QS. al-Mukminun ayat 1. Menurut Kiai Saleh, untuk bisa mencapai khushu', seseorang harus melakukan hal-hal sebagai berikut: (1) tenang anggota tubuhnya. Hati menghadap kepada Allah dan merasa seolah-olah berada di hadapan Allah SWT; (2) Hati merasa takut dan berhati-hati terhadap semua kelakuannya (terhadap siksa Allah), dengan selalu mengagungkan Allah. Hatinya selalu takut (khawf) terhadap siksa Allah; (3) Mengharap ( $r a j \bar{a})$ - semoga amal ibadah dan shalatnya diterima di sisi Allah, dan mengharap pahala Allah;56 (4) Malu kepada Allah, karena merasa tidak bisa menjalankan adab shalat, yaitu selalu ingat pada Allah dan tidak gila atau mabuk, sebagaimana dalam QS. Thaha [20]: 14 dan QS. al-Nisa' [4]: 43; (5) Hudụur al-qalb, yaitu shalat dengan badan dan hati. Keduanya hanya tertuju pada Allah, bukan kepada makhluk; 6) Memanfaatkan shalat sebagai tempat bermunajat kepada Allah SWT. sehingga setiap ayat dan doa yang dilafazhkan harus dipahami dan dihayati makna kandungannya. ${ }^{57}$

\section{d. Taubat}

Menurut Kiai Saleh, taubat seorang hamba digolongkan menjadi dua, yakni taubat haqq Allah dan taubat haqq Adam. Adapun rukun taubat dari dosa haqq Allah ada 3, yaitu: (1) menyesali perbuatan dosa yang telah diperbuatnya; (2) akan berhenti dari dosa yang telah diperbuatnya, (3) me-

54 Ibid., h. 28-29.

$55 \mathrm{Abu}$ al-Qasim 'Abd al-Karim ibn Hawazin al-Qusyairi al-Naysaburi, al-Risālah alQushayriyyah, ditahqiq oleh Ma'ruf Zurayq dan 'Ali 'Abd al-Hamid Balthahji, (Beirut: Dar al-Khayr, t.th.), h. 144-145.

56 Muhammad Shalih, Kitāb Majmū'at..., h. 64-65.

57 Ibid., h. 66-68. 
nyengaja/berjanji tidak akan mengulangi perbuatan dosa lagi. Selain itu, diharapkan ia selalu mengingat-ingat dosa yang dulu pernah dilakukan hingga menyebabkannya menangis dan menyesal, serta mengingat-ingat berapa umurnya sekarang. Kira-kira kurang berapa tahun lagi sisa umurnya. ${ }^{58}$

Sedangkan rukun taubat dari dosa haqq adam ada 4, yaitu: (1) menyesali maksiat yang telah diperbuatnya; (2) berhenti melakukan dosa yang pernah diperbuat; (3) berjanji tidak akan mengulangi perbuatan dosa lagi; (4) meminta halal/maaf/keikhlasan orang yang mempunyai haq kepadanya.59

Adapun jenis dosa itu sendiri, dilihat dari segi kualitasnya, ada dosa besar dan ada dosa kecil. Dosa besar itu banyak macamnya. Diantaranya adalah dosa syirik, murtad, meninggalkan shalat fardhu, membunuh manusia, zina, mencuri walau satu ringgit, merampok, membakar rumah seseorang, minum minuman keras, menuduh zina orang lain atau istri, sumpah pada istri untuk tidak jimak lebih dari 3 bulan, menyamakan istri dengan ibunya (zihar), sumpah palsu, bersaksi bohong, mengakhirkan shalat tanpa ada alasan hingga habis waktunya, meninggalkan shalat Jum'at tanpa ada alasan, walaupun mengerjakan shalat Zhuhur, makan harta riba (rentenir), makan harta anak yatim, durhaka kepada kedua orang tua, jimak pada siang hari bulan Ramadhan, menggunjing kejelekan orang alim atau orang hafal alQur'an, dan jimak dubur, dan lain sebagainya. ${ }^{60}$

Sedangkan dosa kecil, menurut Kiai Saleh banyak sekali macamnya, kirakira ada 500 macam. Diantaranya adalah melihat wanita bukan mahram, menggunjing orang Islam, berbohong, menipu saat transaksi jual beli, memutus persaudaraan, mengurangi timbangan, memukul orang lain tanpa hak, menyuap dalam kasus hukum, tidak mencegah berbuat jelek, makan bangkai atau najis, lupa hafalan al-Qur'annya, menyentuh al-Qur'an tanpa wudlu, bersetubuh dengan istri yang sedang haid, mensetubuhi kerbau atau sapi, merampas hak orang Islam, mendiamkan orang lain lebih dari tiga hari, mendengarkan orang lain saat menggunjing orang, berteriak-teriak saat terjadi kematian atau musibah, atau menyobek sarung atau baju saat terjadi mu-

58 Ibid., h. 39.

59 Ibid., h. 39.

${ }^{60} \mathrm{Ibid}$, h. 35-36.

Walisongo, Volume 20, Nomor 2, November 2012 
sibah, menyeret sarung saat berjalan, memasukkan anak kecil, orang gila, dan najis ke masjid, tertawa kecil dalam shalat yang tidak membatalkan, melangkahi seseorang ketika masuk masjid, kencing dan berak menghadap ke kiblat, membuka aurat saat mandi, mencium istri di siang hari bulan Ramadhan, puasa yang tidak ada bukanya, bersenggolan dengan wanita lain, bersetubuh dengan istri pada masa iddah raj'i, berkhalwat dengan wanita lain yang tidak mahram, perempuan pergi tanpa ada suami atau maḥram, walaupun pergi untuk melaksanakan haji, menawar barang yang sudah ditawar orang lain, menjual barang yang sudah dijual kepada orang lain, dan lainlain. ${ }^{61}$

Semua dosa yang ada, lanjut Kiai Saleh, dapat digolongkan pada dosa zhahir dan dosa batin. Dosa zhahir adalah dosa yang terlihat sebagaimana yang telah disebutkan di atas. Sedang dosa batin adalah dosa yang masuk bagian batini, seperti takabur, hasud, gusar dan sedih saat mendapat musibah, putus asa mencari rahmat Allah, memprovokasi orang Islam agar bermusuhan, 'ujub, sum'ah, benci terhadap hukum Allah, riy $\bar{a}^{\prime}$, dan lain-lain. ${ }^{62}$

\section{Sumber dan Karakteristik Pemikiran Tasawuf Muhammad Shalih al-Samarani dalam Kitab Matn al-Hikam dan Kitāb Majmü'at al-Sharī'ah al-Kāfiyah li 'I-'Awām}

Secara umum, kitab terjamah Matn al-Hikam Muhammad Shalih alSamarani, yang ada 134 bait, adalah terjamah dari kitab asli Matn al-Hikam Ibn 'Atha'illah al-Sakandari. Hanya saja dalam proses penulisannya, Muhammad Shalih atau Kiai Saleh Darat tidak hanya menterjemahkan secara tekstual. Kiai Saleh Darat mencoba memahami makna yang terkandung dalam setiap bait dengan segala kemampuannya.

Dalam proses penjelasan tiap-tiap bait itu, nampak Kiai Saleh tidak hanya sekedar menjelaskan dengan leluasa, yang didasarkan pada teks-teks al-Qur'an dan Hadits, sesuai dengan kemampuan intelektualnya, tetapi tampak juga penjelasan-penjelasan yang dinukil dari pendapat-pendapat para

\footnotetext{
${ }^{61}$ Ibid., h. 36-37.

${ }^{62} \mathrm{Ibid}$, h. 40
} 
sufi yang relevan dengan teks al-Hikam dimaksud, tidak terkecuali pendapat Syaikh Abu Hasan al-Syadzili, pendiri tarekat Syadziliyyah.

Penulis beranggapan, bahwa sumber yang digunakan Kiai Saleh Darat dalam kitab terjamah Matn al-Hikam adalah kitab syarah Hikam yang ada. Seperti karya Ibn 'Abbad al-Randi ${ }^{63}$ dan karya al-Syarqawi.64 Hal ini didasarkan pada kesamaan penjelasan Kiai Saleh Darat dengan apa yang dijelaskan oleh al-Randi maupun al-Syarqawi. 65

Selain itu, Kiai Saleh juga mengutip kitab Ibn 'Atha' Allah al-Sakandari, alTanwīr fi Isqātt al-Tadbìr, untuk menjelaskan bait Hikam, yang juga karya Ibn 'Atha'illah al-Sakandari.66

Dari hasil pembacaan Kiai Saleh dari banyak referensi tentu juga ikut menyumbangkan pemikiran-pemikiran sufistiknya, yang tertuang dalam kitab terjamah Matn al-Hikam itu, yang menjadi pemikiran orisinil sufistiknya Kiai Saleh.

Adapun sumber tasawuf yang digunakan dalam menulis kitab Majmū'at al-Sharīah al-Kāfiyah li 'l-'Awām, sebagaimana yang beliau jelaskan, adalah kitab Ihya' Ulūm al-Dīn karya Imam al-Ghazali.67

Pemikiran tasawuf Saleh Darat yang ada dalam kitab Matn al-Hikam dan Majmū'at al-Sharīah al-Kāfiyah li 'l-'Awām, sangat menekankan terhadap pengamalan ajaran Islam dengan penuh kesadaran dan keikhlasan kepada Allah.

Tasawuf Saleh Darat sangat memberi motivasi kepada mereka yang masih lemah keimanan dan keyakinannya tentang eksistensi Allah. Tulisannya dapat menyadarkan siapa saja yang masih merasa sombong dengan segala kelebihan yang dimilikinya. Karena Hakikat hidup adalah berbakti kepada Allah, bukan menyibukkan diri dengan dunia yang melalaikan sang Pencipta.

${ }^{63}$ Muhammad ibn Ibrahim ibn 'Abbad al-Nafazi al-Randi, Sharh al-Hikam, Bandung: Syirkah al-Ma'arif, t.th.

64 'Abdullah al-Syarqawi, Hāmisy Syarh al-Hikam, Bandung: Syirkah al-Ma'arif, t.th.

65 Lihat misalnya al-Randi, Syarh al-Hikam, juz I, h. 1, dan al-Syarqawi, Hāmish Sharh al-Hikam, juz I, h. 11. Bandingkan dengan Muhammad Shalih, Matn al-Hikam, h. 30-33

66 Lihat Ibn 'Atha'illah al-Sakandarī, al-Tanwīr fi Isqāt al-Tadbīr, Bairut: al-Maktabah alSya'baniyyah, t.th., h. 15-20. Bandingkan dengan Muhammad Shalih, Matn al-Hikam, h. 12-16.

${ }^{67}$ Lihat Muhammad Shalih, Kitāb Majmū'at, h. 278. 
Dari segi penulisan dan cara penyampaiannya, Saleh Darat selalu menggunakan tulisan Arab pegon dengan menggunakan bahasa Jawa. Hal ini beliau lakukan, untuk menolong orang Islam, yang kurang paham atau bahkan tidak mampu bahasa Arab, yang ingin mempelajari ajaran-ajaran Islam yang mayoritas menggunakan bahasa Arab. Hanya saja, kajian kitab semacam ini, sangat sulit diterima oleh mereka yang tidak menguasai bahasa jawa atau tidak dapat membaca Arab pegon.

Melihat pemikiran-pemikiran tasawuf Saleh Darat yang tertuang dalam kitab Matn al-Hikam dan Majmü'at al-Sharī'ah al-Käfiyah li 'l-'Awām, nampaknya Saleh Darat mendasarkan pemikirannya pada tasawuf sunni amali. Beliau lebih menekankan pada pengamalan ajaran Islam secara konsisten, dengan dilandaskan pada teks-teks al-Qur'an dan Hadits. Beliau sangat menolak adanya pemahaman tasawuf falsafi, yakni tasawuf yang ajaran-ajaranya memadukan antara visi intuitif dan visi rasional pengarangnya, khususnya untuk orang awam. Hal ini bisa dipahami, karena untuk memahami tasawuf falsafi, membutuhkan pemikiran dan pengetahuan yang lebih komprehensif, agar tidak menjurus ke arah kemusyrikan atau menyekutukan Allah. Sedang dosa syirik adalah dosa besar yang tidak diampuni oleh Allah SWT.

\section{E. Relevansi Pemikiran Tasawuf Muhammad Shalih al-Samarani di Era Modern}

Seiring dengan kemajuan teknologi dan informasi, segala bentuk fasilitas dan layanan kepada manusia menjadi mudah dan terkesan memanjakan manusia. Namun di balik kemajuan ini, terkadang justru menimbulkan kegersangan rohani orang-orang modern.

Mayoritas kondisi kemanusiaan modern adalah berada dalam wilayah pinggiran eksistensinya, bahkan bergerak menjauh dari pusat eksistensi, yaitu Tuhan. Sebagai akibatnya, masyarakat modern menjadi kehilangan visi keilahian dan melahirkan gejala psikologis yang berupa kehampaan spiritual. Akibatnya, banyak orang yang menderita penyakit psikologis seperti stres, depresi, resah, bingung, gelisah dan seterusnya.

Untuk mengatasi problem spiritual masa kini, yang salah satunya diakibatkan oleh hilangnya visi keilahian setelah manusia bergerak menjauh dari pusat eksistensi, maka tidak ada jalan lain kecuali kembali ke pusat 
eksistensi tersebut.68 Dan jalan yang paling signifikan adalah melalui tasawuf. Karena pembahasan-pembahasan yang ada dalam tasawuf sangat berhubungan erat dengan kondisi psikologis, disamping berhubungan dengan hal-hal yang bersifat gnosis.

Apa yang disampaikan Muhammad Shalih al-Samarani dalam kitab Hikam maupun Majmū'at sangat relevan dengan kondisi psikologis masyarakat modern yang sedang haus dan gersang dengan siraman spiritual, dan membutuhkan ajaran-ajaran spiritual tasawuf. Kajian tasawuf yang disampaikan dapat menguatkan keimanan dan keyakinan seseorang yang rapuh tentang eksistensi Allah SWT.

Apalagi isi dan cara penyampaian kedua kitab tersebut memang didesain untuk orang awam yang tidak menguasai bahasa Arab, yang tidak dapat mengakses sumber-sumber asli secara langsung. Karya Kiai Saleh Darat ini dapat menjadi jembatan yang intelektual spiritual bagi mereka yang menginginkannya.

Hanya saja, karena bahasa penyampaiannya menggunakan bahasa Jawa, maka proses pemahamannya pun membutuhkan kecapakan tersendiri di bidang bahasa Jawa. Apalagi tulisan yang ada dalam kedua kitab tersebut kurang dilengkapi dengan tanda baca titik dan koma, sehingga agak menyulitkan pembacanya.

Selain itu, dengan masih mempelajari bahasa Jawa, secara tidak langsung eksistensi bahasa lokal, bahasa Jawa, akan terjaga dan lestari di tengah maraknya penggunaan bahasa asing di kalangan masyarakat. Dan hingga saat ini, menurut pengamatan penulis, komunitas Saleh Darat masih tetap eksis. Seperti di Pesantren Bareng Kudus Jawa Tengah, maupun di Losari.

\section{F. Kesimpulan}

Pemikiran tasawuf Muhammad Shalih al-Samarani (Saleh Darat) yang ada dalam kitab Matn al-Hikam dan Majmū'at al-Sharīah al-Käfiyah li 'l'Awām, menekankan terhadap pengamalan ajaran Islam dengan penuh kesadaran dan keikhlasan kepada Allah. Saleh darat mendasarkan pemikiran-

68 Masyharuddin, "Ibn Taimiyah dan Pembaharuan Tasawuf" dalam Tasawuf dan Krisis, (Yogyakarta: Pustaka Pelajar, 2001), h. 107. 
nya pada tasawuf sunni amali. Beliau menolak keras pemahaman tasawuf falsafi, khususnya untuk orang awam.

Apa yang disampaikan Muhammad Shalih al-Samarani dalam kitab Hikam maupun Majmū'at sangat relevan dengan kondisi psikologis masyarakat modern yang sedang haus dan gersang dengan siraman spiritual, dan membutuhkan ajaran-ajaran spiritual tasawuf. Apalagi isi dan cara penyampaian kedua kitab tersebut memang didesain untuk orang awam yang tidak menguasai bahasa Arab, hingga mereka tidak dapat mengakses sumbersumber asli secara langsung. Karya Kiai Saleh Darat ini dapat menjadi jembatan yang intelektual spiritual bagi mereka yang menginginkannya.[w] 


\section{BIBLIOGRAFI}

Anwar, Mukhtar dan Solihin, Mukhtar, Ilmu Tasawuf, Bandung: Pustaka Setia, 2006.

Azra, Azyumardi, Jaringan Ulama Timur Tengah dan Kepulauan Nusantara Abad XVII dan XVII, Bandung: Mizan, 1999.

Bruinessen, Martin van, Kitab Kuning, Pesantren dan Tarekat: Tradisi-tradisi Islam di Indonesia, Bandung: Mizan, 1415/1995.

"Kitab Fiqih di Pesantren Indonesia dan Malaysia," Pesantren, no. 1/ Vol. VI, 1989.

Danner, Victor, Ibn 'Ațāillāh's Sufi Aphorisms (Kitab al-Hikam), Leiden: E.J. Brill, 1984.

Hamka, Tasauf Perkembangan dan Pemurniannya, Jakarta: Pustaka Panjimas, 1993.

Ibn 'Atha' Allah, Taj al-Din Ahmad ibn Muhammad ibn 'Abd al-Karim, alSakandari, al-Tanwïr fi Isqāț al-Tadbïr, Bairut: al-Maktabah al-Sya'baniyyah, t.th.

al-Hikam al-'Ațāizyyah wa'l-Munājāh al-Ilāhiyyah, ditashhih oleh Hasan al-Samahi Suwaydan, Damasqus: t.pn., 1998.

Masyharuddin, Ibn Taimiyah dan Pembaruan Tasawuf, dalam Tasawuf dan Krisis, Yogyakarta: Pustaka Pelajar, 2001.

Muchoyyar HS, M., "K.H. Muhammad Salih as-Samarani, Studi Tafsir Faid arRahman fi Tarjamah Tafsir Kalam Malik ad-Dayyan," Disertasi, Yogyakarta: Pascasarjana IAIN Sunan Kalijaga, 2000.

Mulyati, Sri, Tasawuf Nusantara, Rangkaian Mutiara Sufi Terkemuka, Jakarta: Kencana Prenada Media Group, 2006.

Munir, Ghazali, Shalat Jum'at Bergantian, Implementasi Konsep Iman dan Amal Muhammad Salih Ibn Umar as-Samarani dalam Masyarakat Modern, Semarang: Syiar Media Publishing, 2008.

,Tuhan, Manusia, dan Alam, dalam Pemikiran Kalam Muhammad Salih asSamarani, Semarang: Rasail, 2008.

Walisongo, Volume 20, Nomor 2, November 2012 
Qusyairi, Abu al-Qasim 'Abd al-Karim ibn Hawazin, al-Naysaburi, al-Risālah alQushayriyyah, ditahqiq oleh Ma'rūf Zurayq dan 'Ali 'Abd al-Hamid Balthahji, Bairut: Dar al-Khayr, t.th.

Randi, Muhammad ibn Ibrahim ibn 'Abbad al-Nafazi, Sharḥ al-Hikam, Bandung: Syirkah al-Ma'arif, t.th.

Sakandari, Ibn 'Atha'illah, Latạ̄if al-Minan, ditahqiq oleh 'Abd al-Halim Mahmūd, Kairo: Dar al-Kutub, 1974.

Salim, Abdullah, Majmūat al-Sharīah al-Kāfiyah li 'l-Awwām karya Shaikh Muhammad Shālih Ibn 'Umar al-Samārānī, Seri Disertasi, Jakarta: IAIN Syarif Hidayatullah, 1994.

Samarani, Haji Muhammad Shalih ibn 'Umar, Hażā al-Kitāb Matn al-Hikam li Sayyidī al-Shaikh Ahmad ibn 'Ațā' Allāh al-Sakandarī, Semarang: Thoha Putra, t.th.

Hażā Kitāb Majmū'at al-Sharīah al-Käfiyah li '-'Awām Mutarajjimah bi Lughat al-Jāwiyyah al-Mrikkiyyah, al-Maktabah al-Mishriyyah, Syirbun, t.th.

Shabir, Muslich, Studi Kitab Munjiyat: Menyingkap Konsep Kiai Saleh Darat tentang Perbuatan yang Membinasakan dan yang Menyelamatkan Manusia, Semarang: Puslit IAIN Walisongo, 2007, Vol. XV, No. 1, Mei 2007.

Siregar, A. Rivay, Tasawuf dari Sufisme Klasik ke Neo Sufisme, Jakarta: Raja Grafindo Persada, 2002.

Solihin, M., Sejarah dan Pemikiran Tasawuf di Indonesia, Bandung: Pustaka Setia, 2001.

Melacak Pemikiran Tasawuf di Nusantara, Jakarta: Raja Grafindo Persada, 2005.

Syarqawi, 'Abd Allah, Hāmish Sharḥ al-Hikam, Bandung: Syirkah al-Ma'arif, t.th. 